\title{
Ventricular septal defect as a consequence of chronic bicuspid aortic valve infective endocarditis
}

\section{(1DAnto Stažićc ${ }^{*}$, \\ (1) Grgur Dulić1,2, \\ - Sandra Makarović1,2, \\ Olvica Bošnjak', \\ ONora Pušeljić', \\ DLuka Švitek', \\ - Mihaela Roguljić', \\ (DTanja Mikulandra', \\ (C) Kristina Selthofer- \\ Relatić1,2}

'University Hospital Centre Osijek, Osijek, Croatia

${ }^{2}$ Josip Juraj Strossmayer University of Osijek, Faculty of Medicine, Osijek, Croatia
RECEIVED:

March 28, 2021

ACCEPTED:

April 2, 2021

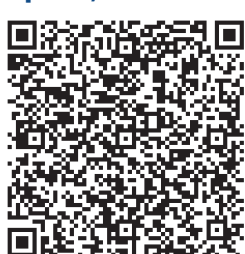

KEYWORDS: bicuspid aortic valve, infective endocarditis, ventricular septal defect, tooth infection. CITATION: Cardiol Croat. 2021;16(5-6):185-6. | https://doi.org/10.15836/ccar2021.185

*ADDRESS FOR CORRESPONDENCE: Anto Stažić, Klinički bolnički centar Osijek, Josipa Huttlera 4, HR-31000 Osijek, Croatia. Phone: +385-95-3877-276 / E-mail: anto.stazic1@gmail.com

ORCID: Anto Stažić, https://orcid.org/0000-0002-4429-8297 • Grgur Dulić, https://orcid.org/0000-0003-2295-3913 Sandra Makarović, https://orcid.org/0000-0002-7487-1189 • Ivica Bošnjak, https://orcid.org/0000-0002-0223-4287 Nora Pušeljić, https://orcid.org/0000-0002-6687-7804 • Luka Švitek, https://orcid.org/0000-0003-0208-5821 Mihaela Roguljić, https://orcid.org/0000-0002-4343-148X • Tanja Mikulandra, https://orcid.org/0000-0003-2766-1653 Kristina Selthofer-Relatić, https://orcid.org/0000-0002-9890-6489

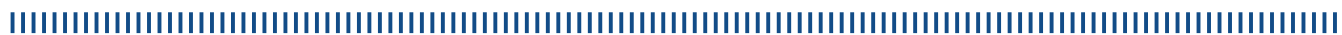

Introduction: Native valve infective endocarditis (IE) is a result of bacteremia with high mortality rate of about 30\%. Optimal outcome of valve IE depends on timely diagnosis, etiology, antibiotic treatment, involved valve, patient age, comorbid diseases, extent and location of metastatic complications, and the duration of the infection. Besides invasive procedures and mechanical damage breaking these boundaries, it has also been shown that routine daily activities such as tooth brushing, and chewing could lead to bacterial penetration of the bloodstream. Bicuspid aortic valve (BAV) is the most common form of congenital heart disease with 30 -fold higher risk of IE than in the general population. Common complications are congestive heart failure (HF), peri annular abscesses and systemic embolization. Ventricular septal defect (VSD) is often a predisposing factor for the development of IE, but only rarely occurs as a complication of the condition..$^{1-4}$ This case report presents the outcome of a patient with BAV that was complicated with a chronic form of BAV IE caused by inadequate tooth hygiene and resulted in the rare IE complication of VSD.

Case report: In a 43-year-old obese male patient mid-range stenosis and mild regurgitation of aortic valve (AV), probably BAV, was detected by transthoracic echocardiography (TTE). Tooth caries were detected, and antibiotic prophylaxis was recommended. Eight months later, the patient was hospitalized because of intermittent fever. TTE imaging due to the patient's obesity were poor quality, while patient cooperation for transesophageal echocardiography was limited. He felt better after antibiotic therapy and went home. One month later, he was readmitted because of HF caused by chronic BAV IE showing severe aortic regurgitation, aortic valve abscess and, consequently, a membranous VSD (Figure 1). Cardiac surgery with mechanical prosthesis valve replacement and septal defect patching was performed (Figure 2)
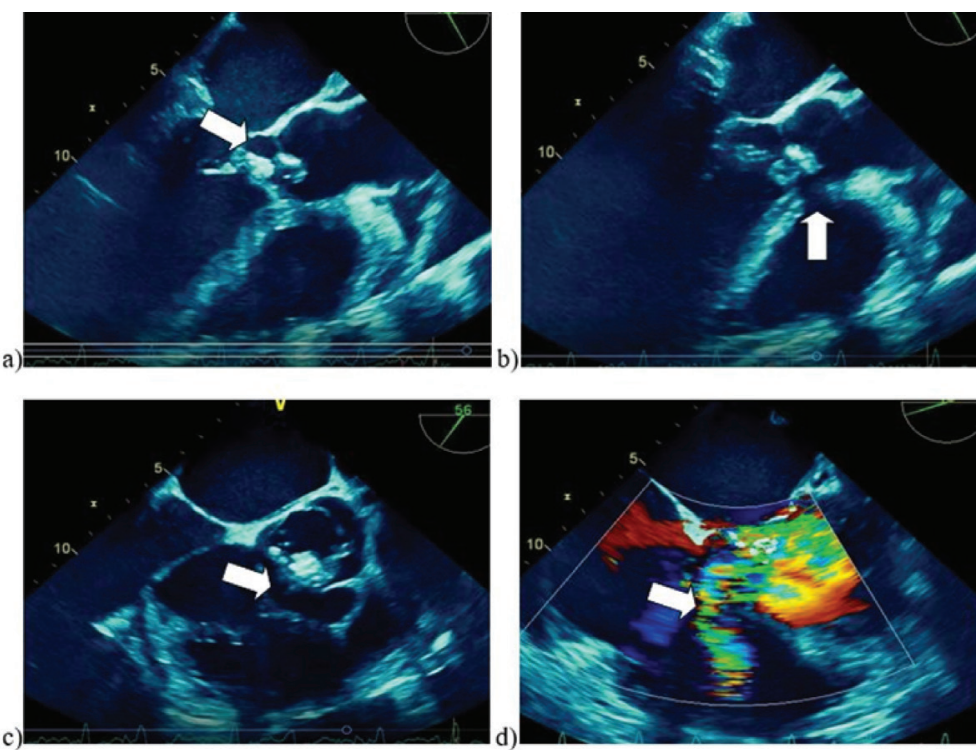

FIGURE 1. Infective endocarditis of the bicuspid, aortic valve by transesophageal echocardiography (a); ventricular septal defect (did not exist before) (b); bicuspid, aortic valve abscesses (c); ventricular septal defect by color Doppler (d). 
a)

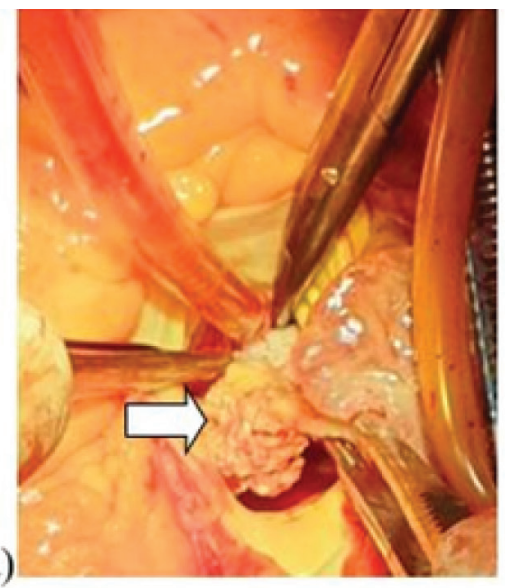

b)

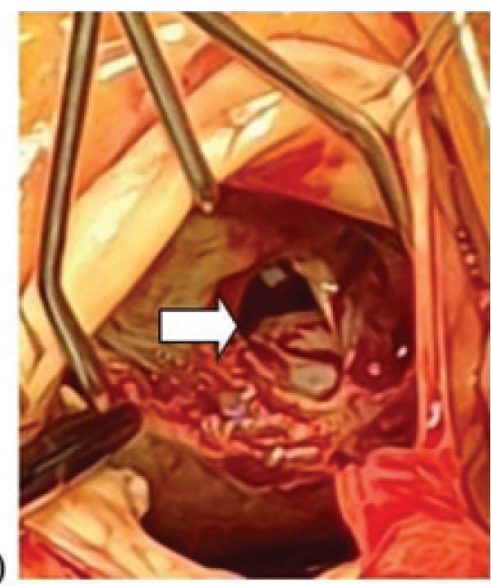

c)

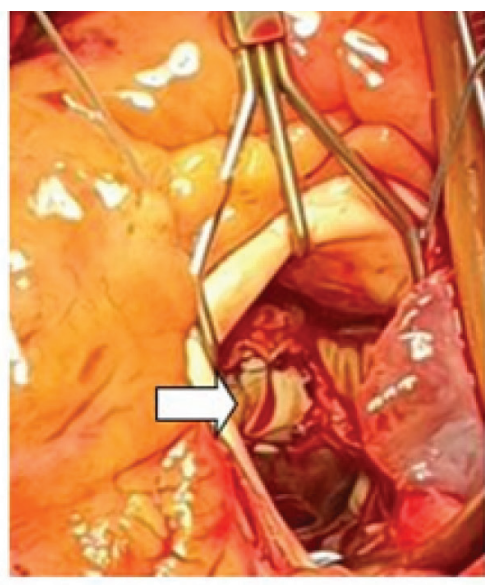

FIGURE 2. Infective mass on the aortic, bicuspid valve (a); ventricular septal defect due to infective endocarditis (b); patch plastic of ventricular septal defect (c).

Conclusion: This case highlights the need for early suspicion of IE, precise cardiac imaging and early investigation for comorbid diseases. Patient cooperation and understanding of the risk are crucial parts of prevention or treatment, or the spread of IE could become complicated with rarer and more complex forms of disease.

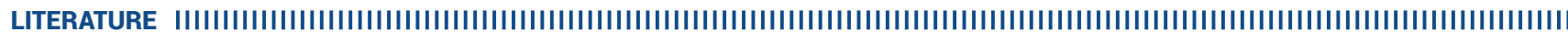

1. Dajani AS, Taubert KA, Wilson W, Bolger AF, Bayer A, Ferrieri P, et al. Prevention of bacterial endocarditis. Recommendations by the American Heart Association. Circulation. 1997 Jul 1;96(1):358-66. https://doi.org/10.1161/01.CIR.96.1.358

2. Siu SC, Silversides CK. Bicuspid aortic valve disease. J Am Coll Cardiol. 2010 Jun 22;55(25):2789-800. https://doi.org/10.1016/j.jacc.2009.12.068

3. Durden RE, Turek JW, Reinking BE, Bansal M. Acquired ventricular septal defect due to infective endocarditis. Ann Pediatr Cardiol. 2018 Jan-Apr;11(1):100-102. https://doi.org/10.4103/apc.APC_130_17

4. Habib G, Lancellotti P, Antunes MJ, Bongiorni MG, Casalta JP, Del Zotti F, et al; ESC Scientific Document Group. 2015 ESC Guidelines for the management of infective endocarditis: The Task Force for the Management of Infective Endocarditis of the European Society of Cardiology (ESC). Endorsed by: European Association for Cardio-Thoracic Surgery (EACTS), the European Association of Nuclear Medicine (EANM). Eur Heart J. 2015 Nov 21;36(44):3075-3128. https://doi.org/10.1093/eurheartj/ehv319 